OPEN ACCESS

Edited by: Marcos Vinicius Calfat Maldaun, Hospital Sirio Libanes, Brazil

Reviewed by: Giovanni Raffa, University of Messina, Italy Jason M. Miska, Northwestern University, United States

*Correspondence: Guixiang Liao liaoguixiang@163.com

Specialty section: This article was submitted to

Neuro-Oncology and

Neurosurgical Oncology, a section of the journal

Frontiers in Oncology

Received: 27 June 2020 Accepted: 30 September 2020 Published: 06 November 2020

Citation:

Khan M, Zhao Z, Arooj S, Zheng T and Liao G (2020) Lapatinib Plus Local Radiation Therapy for Brain Metastases From HER-2 Positive Breast Cancer Patients and Role of Trastuzumab: A Systematic Review and Meta-Analysis.

Front. Oncol. 10:576926. doi: 10.3389/fonc.2020.576926

\section{Lapatinib Plus Local Radiation Therapy for Brain Metastases From HER-2 Positive Breast Cancer Patients and Role of Trastuzumab: A Systematic Review and Meta-Analysis}

\author{
Muhammad Khan ${ }^{1,2}$, Zhihong Zhao ${ }^{3}$, Sumbal Arooj ${ }^{1,4}$, Tao Zheng ${ }^{1}$ and Guixiang Liao ${ }^{1 *}$ \\ ${ }^{1}$ Department of Radiation Oncology, Shenzhen People's Hospital, The First Affiliated Hospital of Southern University of \\ Science and Technology, Shenzhen, China, ${ }^{2}$ Department of Oncology, First Affiliated Hospital of Anhui Medical University, \\ Hefei, China, ${ }^{3}$ Department of Nephrology, Shenzhen People's Hospital, Second Clinical Medicine Centre, Jinan University, \\ Shenzhen, China, 4 Department of Biochemistry, University of Sialkot, Sialkot, Pakistan
}

Background: Intracranial activity of lapatinib has been demonstrated in several studies in patients with human epidermal growth factor receptor-2 positive breast cancers (HER-2+ BC). Stereotactic radiosurgery (SRS) has been increasingly used as the local therapy for brain metastases in breast cancer patients. Increased objective response rate was observed for lapatinib plus whole brain radiotherapy (WBRT) is such patients with high toxicity.

Objective: We seek to obtain clinical evidence of synergistic efficacy of lapatinib in combination with radiation therapy, in particular, SRS.

Materials and methods: We carried out a comprehensive research using the following databases: PubMed; Medline; EMBASE; Cochrane library. These databases were searched until 10 June 2020. PRISMA guidelines were followed step by step for carrying out this systematic review and meta-analysis. Review Manager v 5.4 software was used for statistical evaluation of data.

Results: Overall 6 studies with 843 HER-2 positive breast cancer patients (442 HER-2 amplified disease, 399 luminal B disease) were included in this systematic review and meta-analysis. A total 279 patients had received lapatinib in addition to HER-2 antibody (trastuzumab) plus/minus chemoradiotherapy, while 610 patients had received trastuzumab-based management or only chemoradiotherapy. Lapatinib-based management of BM was associated with significant increase in overall survival (HR 0.63 $[0.52,0.77], p<0.00001$ ). Combination of the two (trastuzumab plus lapatinib) was associated with increased survival advantage compared to each agent alone $(0.55[0.32$, 0.92], $p=0.02)$. SRS in combination with lapatinib was associated with increased local control (HR $0.47[0.33,0.66], p=0.0001)$. Ever use of lapatinib with SRS was associated 
an increased survival as reported in two studies (Shireen et al.: 27.3 vs. 19.5 months, $p=$ 0.03; Kim et al.: 33.3 vs. 23.6 months, $p=0.009$ ). Kim et al. also revealed significant increase in intracranial activity with concurrent lapatinib reporting $57 \%$ complete response compared to $38 \%(p<0.001)$ and lower progressive disease rate of $11 \mathrm{vs.} 19 \%$ ( $p<$ 0.001). Risk of radiation necrosis was decreased with lapatinib use.

Conclusions: Lapatinib has shown intracranial activity and yielded better survival for HER-2+ BC patients with BMs. SRS in combination with ever use of lapatinib had better local control and were associated with better survival. Radiation necrosis risk was reduced with the use of lapatinib.

Keywords: lapatinib, stereotactic radiosurgery (SRS), brain metastases (BM), overall survival (OS), radiation necrosis (RN), human epidermal growth factor receptor-2 (HER-2) positive breast cancer

\section{INTRODUCTION}

Breast cancer is the leading type of cancer in women according to the estimated number of new cases in 2020 (1-3). An estimated 276,480 new cases of breast cancer will be diagnosed with an estimated 42,170 breast cancer deaths will occur in women $(1,2)$. A surge of $0.3 \%$ per year from 2007 to 2016 has been observed in invasive breast cancer incidence rate $(1,2)$. Mortality rate, on the other hand, has been declined by 40\% from 1989 (33.2/100,000) to $2017(19.8 / 100,000)(1,2)$. These improvements in management of breast cancer reflects the advancements in screening and awareness and treatment paradigm (1-6). Traditionally, breast cancer patients are managed with surgery, chemotherapy and radiation therapy (3-6). Advancements in the molecular understanding have added newer targeting agents to the treatment regimen that target various breast cancer subtypes according to the receptors expressed by breast cancer cells such as Luminal A (ER/PR positive/HER2 negative), HER2 (HER2 positive/ER/PR negative), luminal B (triple positive), and basal (triple negative) (6-8). In the case of luminal B and HER-2 amplified disease, these advancements include: the endocrine therapy for ER/PR positive breast cancer, monoclonal antibodies (trastuzumab and pertuzumab), multi-kinase inhibitors (lapatinib, neratinib, and tucatinib), and antibody-drug conjugates (ADC) targeting the HER-2 overexpressing breast cancers (6-12). Furthermore, molecular targeted agents targeting various subsequent intracellular signaling pathways such as inhibitors of cyclin-dependent kinases 4 and 6 (CDK4/6), phosphatidylinositol 3-kinase (PI3K), protein kinase B (Akt), and mammalian target of rapamycin (mTOR) pathways have also been developed to enhance the outcomes (6-9). These advancements have led to rapid improvement in the outcome for breast cancer patients in recent years as also manifested by the decrease in death rate of $1.3 \%$ per year from 2013 to 2017 . 5and 10-year survival rates for women with invasive breast cancer are 91 and $84 \%$, respectively $(1,2)$.

Broadly, breast cancer is categorized into in situ carcinoma and invasive carcinoma $(3,4,13,14)$. Invasive breast cancer invades or metastasize to other parts or organs of the body and is composed of mainly two categories: infiltrating lobular carcinoma (ILC) and infiltrating ductal carcinoma (IDC) (13,
14). ILC accounts for $10-15 \%$, while IDC makes up the $80 \%$ of breast cancer diagnosis $(7,8)$. Breast cancer is the second most frequent cancer to cause brain metastases (15-25\%) after lung cancer (40-50\%) (15). Fractionated WBRT has only managed limited local control (median intracranial failure: 3-5 months) and median survival time around $3-4$ months $(16,17)$. SRS alone or in combination with WBRT, surgery, or both were superior to WBRT alone in prolonging the survival in breast cancer patients with brain metastases (18). SRS alone has reported impressive local control rates between 90 and $94 \%$ and median survival between 10 and 16 months (16). Hence, SRS alone has emerged as main treatment for brain metastases alone or in combination $(19,20)$. However, various breast cancer subtypes also have responded distinctly from the prognostic point of view to surgical and radiotherapeutic management (21-24). Sperduto et al. have revealed luminal A and luminal B treated with surgery, SRS, and WBRT alone or in various combinations were superior according to time from primary diagnosis to brain metastases (TPDBM) (LA: 54.4, LB: 47.4, HER2: 35.8, and B: 27.5, months ( $\mathrm{p}<0.01$ ), and survival from primary diagnosis (PD survival) (LA: 54.4, LB: 47.4, HER2: 35.8, and B: 27.5 months, $\mathrm{p}<0.01$ ) (LA: 72.7, LB: 90.3, HER2: 66.4, and B: 39.6 months, $\mathrm{p}<0.01$ ) (23). On the other hand, patients with HER2 positive patients (luminal B and HER2 positive) reported better survival from the time of BM diagnosis (BM survival) compared to other two types (LB: 22.9, HER2: 17.9, LA: 10, and B: 7.3 months, p < 0.01) (23). Similarly, in a separate retrospective study (n-131), breast cancer patients were treated with SRS alone for their brain metastases reported a trend towards better survival in patients with HER2 positive subgroups (LB: 26, HER2: 23, LA: 16, and B: 7 months, $\mathrm{p}<0.001)(24)$. These outcomes suggest HER2 overexpressing $\mathrm{BC}$ patients with brain metastases are placed at better prognosis if treated with SRS alone or in combination with other treatment regimens (surgery, WBRT).

Human epidermal growth factor receptor 2 (EGFR-2/HER-2) also known as erythroblastic leukemia viral oncogene homolog 2 (ERBB2) protein, is overexpressed by around 20 to $30 \%$ of breast cancers $(25,26)$. HER2-positive and triple-negative status were identified as risk factors for the development of BM (21). About one third of the HER-2 overexpressing metastatic breast cancer patients develop brain metastases (27). Before the advent of 
targeted therapy and chemotherapeutic agents against HER-2 positive breast cancer, HER-2 positive status was associated with worst overall survival compared to HER-2 negative BC $(28,29)$. Trastuzumab, an anti-HER-2 monoclonal antibody, have been developed and approved for HER2 positive metastatic breast cancer patients along with chemotherapy based on the results of phase I and phase II trials (9). Despite improvement in overall survival with trastuzumab, it is deemed ineffective against prevention of $\mathrm{BM}$ development and intracranial activity due to its heavy molecular weight (30-35). In fact, treatment with trastuzumab was related to higher $\mathrm{BM}$ incidence in these patients (32-35). It could be attributed to longer survival and better control of systemic disease. Moreover, 25\% of patients relapse after adjuvant trastuzumab-based treatment for HER-2 BC patients (26). HER-2 positive metastatic breast cancer patients progressing on trastuzumab-based therapy were allowed to be treated with lapatinib, a dual tyrosine-kinase inhibitor of EGFR and HER2, in combination with capecitabine; FDA had approved the combo "lapatinib plus capecitabine" on March 13, 2007 (10). As opposed to trastuzumab, lapatinib is a small molecule and it is suggested it may penetrate BBB to have efficacy in the brain as well. Lapatinib was shown to prevent the development of brain metastases in HER-2 positive breast cancer patients $(27,36)$. Lapatinib as monotherapy had shown a modest intracranial activity in trastuzumab-pretreated patients with progressive CNS disease after radiotherapy $(27,37)$. A $20 \%$ intracranial response rate was observed in patients treated with lapatinib plus capecitabine combination (37).

There is growing interest in combining the radiation therapies and targeted or immune therapies in order to seek synergism between the treatments. Hence, lapatinib with WBRT was investigated for treating HER-2 positive brain metastases. Though, an objective response rate of $79 \%$ was achieved, the combination was not feasible due to safety concerns (38). Similarly, several retrospective studies have also investigated the concurrent use of lapatinib with radiation therapy (39-44). The results are contradicting with no established recommendations in this direction. Therefore, we have undertaken this systematic review and meta-analysis in order to synthesize a meta-outcome for a better clinical perspective.

\section{MATERIALS AND METHODS}

This "systematic review and meta-analysis" was undertaken according to the guidelines provided by the "Preferred Reporting Items for Systematic Reviews and Meta-Analyses" (PRISMA) (45). A protocol of this study is registered on PROSPERO: CRD42020191615.

\section{Inclusion Criteria}

\section{Patients and Study Types}

Comparative studies involving breast cancer patients with brain metastases treated with lapatinib in conjunction with SRS/WBRT or SRS only. Comparative studies with any experimental design (retrospective, prospective, clinical trial, and randomized controlled trials) were allowed for selection.

\section{Types of Interventions}

Lapatinib, a dual tyrosine kinase inhibitor interrupting both HER2/ neu and epidermal growth factor receptor pathways, in conjunction with SRS/WBRT was labeled as the "Experimental intervention group" and SRS/WBRT only as the "Control intervention group".

\section{Outcomes of Interest}

Efficacy outcomes such as survival, brain control, and brain objective responses, and safety outcomes mainly the adverse events related to treatment. Overall survival was characterized as the primary outcome of interest while all other outcomes were of secondary interest to our analysis.

\section{Search Strategy Databases}

We carried out a comprehensive research using the following databases: PubMed; Medline; EMBASE; Cochrane library. These databases were searched until 10 June 2020. Various key search terms were used with English language restriction. As well, various studies' references were search for relevant studies.

\section{Study Selection}

Studies while screening for titles and abstracts were incorporated into the Endnote X9 software for organizing, further screening, and scrutiny. Duplicate studies were removed after proper assessment. Studies were selected or rejected according to inclusion and exclusion criteria by two independent reviewers. Full text assessment was carried out for selected studies. Any disagreement was resolved by mutual consensus between reviewers.

\section{Data Extraction}

Data was extracted and incorporated into the data collection form provided by Cochrane organization named as "The Cochrane Collaboration Data Collection form-RCTs and non-RCTs". Extracted data included various studies' attributes and patients' baseline characteristics. Attributes of the studies included study design, number of participants, year of publication, time period, treatment regimens, main outcomes for the whole study population, and median follow ups. Baseline characteristics of the patients included age, sex, performance status, number of brain metastases, previous therapies, subsequent systemic, or other therapies. Comparative outcome data was also recorded such overall survival, local and distant control, and safety measures.

\section{Assessment of Risk for Bias}

Downs and Black checklist was used for risk of bias assessment (46). Downs and Black checklist developed for the assessment of the methodological quality of non-randomized interventional studies consists of 27 questions covering four aspects of quality assessment namely reporting, external validity, internal validity (bias and confounding), and statistical power. A single point is given for each question if the answer is in affirmative and 2 points in case of one question in reporting section. Reporting section consists of 10 questions, and external validity of 3 questions. Internal validity is comprised of 13 questions and involves 2 sections; bias, and confounding. We used the modified version of Downs and Black checklist in which statistical power question is 
answered as yes or no with a single point score as compared to original checklist in order to simplify calculation and avoid ambiguity (47). Gradation was assigned according to score as “excellent” (24-28 points), "good” (19-23 points), "fair” (14-18 points) or "poor" (<14 points).

\section{Measurement of Treatment Effect and Data Synthesis}

Hazard ratios for survival time were recorded if given in the study or extracted from K-M curves using Digital Equalizer software and the methods described in the study by Tierney et al. for incorporating summary time-to-event data into metaanalysis (48). Similar procedure was followed for local control rates. Pooling of hazard ratios was done using RevMan v 5.4 software $(49,50)$. Inverse variance or $\mathrm{M}-\mathrm{H}$ method was used for pooling hazard ratios or odds ratios, respectively. Fixed effects model or random effects model was adopted according to the level of heterogeneity $\left(\mathrm{I}^{2}\right)$. Heterogeneity more than $50 \%$ was considered as moderate and criteria for adopting random effects model (51). Significance level was set at p value less than 0.05.

\section{RESULTS}

Overall six studies were identified meeting the inclusion criteria through robust research strategy and study selection process (39-44) (Figure 1). A total of 843 HER-2 positive breast cancer patients with brain metastases treated with radiation therapy as local treatment plus/minus chemotherapy and anti-HER2 therapy (trastuzumab/lapatinib) over a time period between 1997 to 2015 constituted the participants of this meta-synthesis.
442 had HER-2 amplified disease while 399 had luminal B disease. A total of 279 patients had been treated with lapatinib plus/minus anti-HER2 antibody, and 610 patients were either treated with ant-HER2 antibody (mainly trastuzumab) or in some cases without any anti-HER2 therapy $(\mathrm{n}=227)$. Patients with luminal $\mathrm{B}$ disease were also treated with hormone therapy. SRS as local therapy plus/minus WBRT was mainly used in all studies ( $\mathrm{n}=$ 404). While WBRT alone was used in three studies only, it constituted the main treatment option according to the number of patients $(\mathrm{n}=484)(39,40,42)$. All the included studies were retrospective in nature and classified as class III evidence (39-44). The studies were graded as "fair" or "good" after quality assessment as illustrated in Table 1. All the studies scored low on selection bias and power (39-44). The studies graded fair had also scored a bit lower on reporting assessment $(39,41,43)$.

\section{Baseline Characteristics of the Patients}

Baseline characteristics of the patients were mostly matched without any significant differences except for age, KPS, and prior local therapy. Shireen et al. study $(n=126)$ lapatinib receiving participants $(n=47)$ were younger in age $(\mathrm{p}=0.025)$, and had partially better KPS score $(\mathrm{p}=0.091)(44)$. Participants in the four arms of Yap et al. study also had age differences (0.089) (40). While in the study by Kim, et al., concurrent lapatinib group patients had received prior WBRT for a greater number of lesions ( 80 vs. $53 \%$, $\mathrm{p}<0.001$ ), and SRS boost to WBRT was also received by fewer lesions ( 2 vs. $10 \%, \mathrm{p}=0.005$ ). As well, a greater number of lesions treated with SRS alone had also been resected previously (2 vs. 19\%, $\mathrm{p}<0.001$ ) (43). Except for these differences, no other baseline characteristics differences were noticed such as extracranial disease,

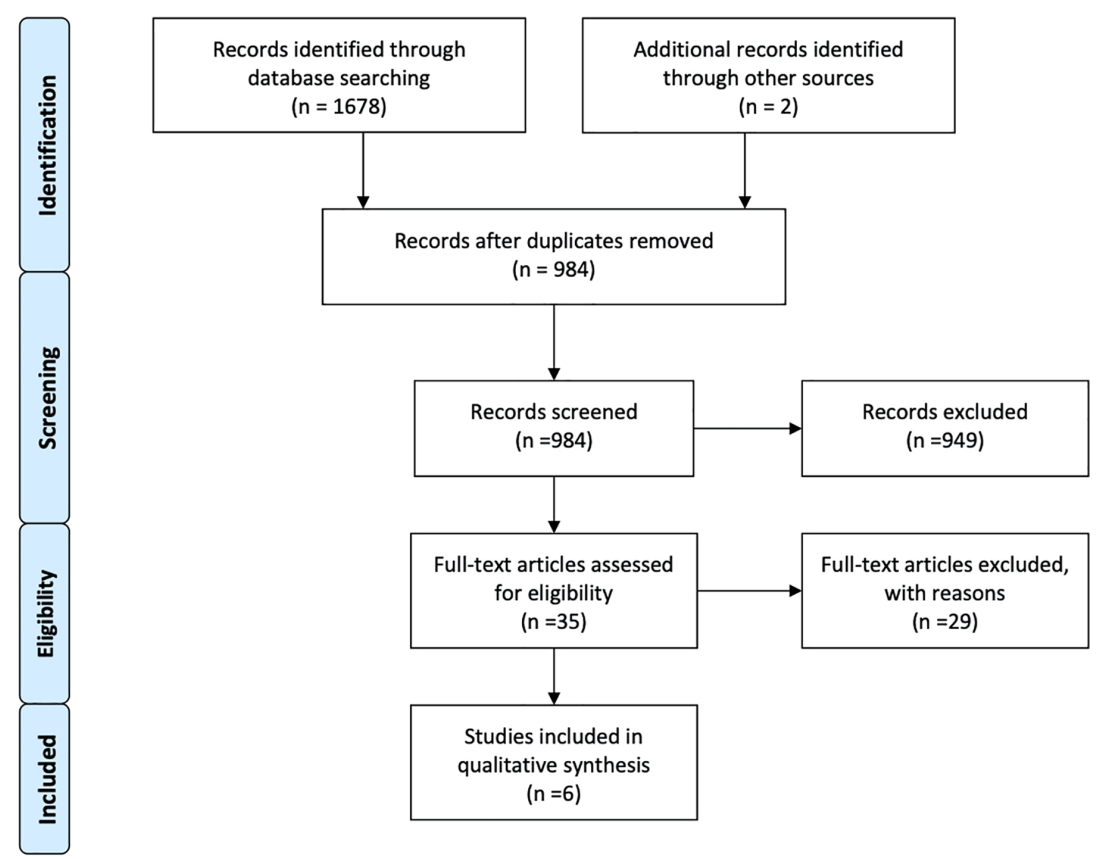

FIGURE 1 | PRISMA flow diagram of search strategy and study selection. 
number of brain metastases, RPA classification and DS-GPA categorization (39-44). General characteristic of the studies and patients are outlined in Tables 1, 2.

\section{Overall Survival}

Overall survival was analyzed at several levels depending on the status of lapatinib use (ever/concurrent), combination with trastuzumab, and the type of radiation therapy received (WBRT/SRS).

\section{Lapatinib vs. Non-Lapatinib-Based Therapy}

First, lapatinib (ever used or given concurrently) plus/minus trastuzumab (given sequentially or concurrently) plus/minus chemotherapy with local therapy for BM compared to BM patients who had never used lapatinib and may or may not have utilized trastuzumab and cytotoxic chemotherapy but had undergone local surgical and/or radiation therapy (WBRT and SRS) for brain metastases. Patients receiving lapatinib concurrently or any time during the course of their disease for BM was associated with improved survival compared to patients without any lapatinib use. All the six studies reported survival outcome involving 843 patients. Meta-analysis of OS revealed a significant improvement in overall survival based on the results from five studies (HR 0.63 [0.52, 0.77], p < 0.00001) (Figure 2; Outcome 1.1.1) $(39-42,44)$. Kim et al. also revealed a significant increase in survival benefit (MST: 33.3 vs. 23.6 months, $\mathrm{p}=$ $0.009)$ for patients ever $(n=43)$ receiving lapatinib as compared to never $(\mathrm{n}=41)(43)$.

\section{Survival Subgroup Analysis Lapatinib vs. No Anti HER2 Therapy}

Two studies had reported the outcome for patients receiving lapatinib compared to patients that had received no anti-HER2 therapy at all. Pooled hazard ratio revealed that any use of lapatinib was significantly better in comparison to lack of anti-HER-2 therapy (HR $0.41[0.28,0.62], \mathrm{p}<0.0001)$ (Figure 2; Outcome 1.1.2) $(39,40)$.

\section{Lapatinib vs. Trastuzumab-Based Therapy}

In several studies, the control group were exposed trastuzumab. In this case, lapatinib use was associated with significant increase in survival compared to the use of trastuzumab as the only antiHER2 therapy (HR 0.67 [0.54, 0.84], p = 0.0004) (Figure 2; Outcome 1.1.3) (39-42, 44).

\section{Lapatinib Alone vs. No Lapatinib Therapy}

Yap et al. also reported the comparative outcome for patients receiving only lapatinib as anti-HER2 therapy (40). Metaanalysis revealed no survival advantage (HR $0.72[0.47,1.10]$, $\mathrm{p}=0.12$ ) (Figure 2; Outcome 1.1.4). However, this result was mainly based on the results from single study (40).

\section{Lapatinib Plus Trastuzumab vs. Lapatinib/ Trastuzumab Alone}

Moreover, use of both lapatinib plus trastuzumab sequentially or concurrently was shown to be superior compared to each given alone (0.55 [0.32, 0.92], $\mathrm{p}=0.02$ ) (Figure 2; Outcome 1.1.5) (40). Nonetheless, the effect was much better compared to 
TABLE 2 | Baseline characteristics of patients and main outcomes of interest.

\begin{tabular}{|c|c|c|c|c|c|c|c|}
\hline $\begin{array}{l}\text { Characteristics/ } \\
\text { studies }\end{array}$ & Bartsch et al. (39) & Yap, et al. (40) & Yomo, et al. (41) & Miller et al. (42) & Kim et al. (43) & Shireen et al. (44) & This study \\
\hline $\begin{array}{l}\text { Comparative } \\
\text { groups }\end{array}$ & Lapatinib/no lapatinib & Lapatinib/no lapatinib & $\begin{array}{l}\text { Lapatinib/no } \\
\text { lapatinib }\end{array}$ & Lapatinib/no lapatinib & Lapatinib/no lapatinib & Lapatinib/no lapatinib & $\begin{array}{l}\text { Lapatinib/no } \\
\text { lapatinib }\end{array}$ \\
\hline No. of patients & $80(15 / 65)$ & $280(58 / 222)$ & $40(24 / 16)$ & $233(89 / 187)$ & $84(43 / 41)$ & $126(47 / 79)$ & $\begin{array}{l}843(276 / \\
610)\end{array}$ \\
\hline $\begin{array}{l}\text { Age (median } \\
\text { [range]) (years) }\end{array}$ & $53(28-77)$ & $\begin{array}{l}52(25-81) \\
(p=0.084)\end{array}$ & $58.5(37-72)$ & $\begin{array}{l}52(23-80) \\
53(28-87)\end{array}$ & 52 [31-84] & $\begin{array}{l}54(31-84) \\
(p=0.025)\end{array}$ & \\
\hline HER2+ & 42 & 159 & 40 & 99 & 51 & 51 & 442 \\
\hline HR & 38 & 119 & & 134 & 33 & 75 & 399 \\
\hline $\begin{array}{l}\text { Lapatinib +/- HER2 } \\
\text { mAb }\end{array}$ & 15 & 30 & 24 & 89 & 43 & 47 & 248 \\
\hline Transtuzumab & 28 & 56 & 34 & 187 & 64 & 55 & 424 \\
\hline Both & - & 28 & - & - & - & - & 28 \\
\hline $\begin{array}{l}\text { No anti-HER2 } \\
\text { therapy }\end{array}$ & 37 & 166 & - & - & - & 24 & 227 \\
\hline $\begin{array}{l}\text { Concurrent } \\
\text { lapatinib }\end{array}$ & - & - & - & - & 18 & 24 & 42 \\
\hline SRS +/- WBRT & 40 & 32 & 40 & 82 & 84 & 126 & 404 \\
\hline WBRT & 40 & 251 & - & 193 & - & - & 484 \\
\hline Surgery & - & 35 & - & 35 & - & - & 70 \\
\hline Median OS & $\begin{array}{l}\text {-Anti-HER2: } \\
\text { HR: } 0.29 ; 95 \% \mathrm{Cl}: 0.16- \\
\text { 0.54; } p<0.001 \\
\text { Lapatinib: } \\
\text { HR: } 0.279 ; 95 \% \mathrm{Cl}: 0.1- \\
\text { 0.76; } p=0.012\end{array}$ & $\begin{array}{l}\text {-Anti-HER2: } \\
\text { MST: } 18.5 \text { vs. } 5.7, p<0.001 \\
\text {-Lapatinib: } \\
\text { Both agent: } 25.9 \text { (18.5-30.1); Lp } \\
\text { alone: } 21.4 \text { (12.5-27.1); T alone: } \\
\text { 10.5 (8.3-17.7); No anti-HER2: } \\
\text { 5.7 (4.2-8.9), } p<0.001\end{array}$ & $\begin{array}{l}\text { MST: } 19.5 \text { vs. } 15 \\
p=0.530\end{array}$ & $\begin{array}{l}\text { MST: } 21.1 \text { vs. } 15.4 \\
\text { months; } p=0.03\end{array}$ & $\begin{array}{l}\text {-Concurrent: } \\
\text { MST: } 40.4 \text { vs. } 25.1 \text { months }(p=0.155) \\
\text {-Ever use: } \\
\text { MST: } 33.3 \text { vs. } 23.6 \text { months }(p=0.009\end{array}$ & $\begin{array}{l}\text { MST: } 27.3 \text { vs. } 19.5 \\
\text { months, } p=0.03\end{array}$ & \\
\hline $\begin{array}{l}\text { Objective response } \\
\text { rate (ORR) }\end{array}$ & - & - & - & - & $\begin{array}{l}\text {-Concurrent: } \\
\text { CR: } 35 \text { vs. } 11 \%, p=0.008 \\
\text { ORR: (CR + PR, } 75 \text { vs. } 57 \%, P=0.121) \\
\text { PD: } 25 \% \text { vs. } 43 \%, p=0.121 \\
\text { MBOR: } 69 \text { vs. } 54 \%(p=0.037) \\
\text {-Lesion-specific BOR: median } 100 \text { vs. } \\
70 \% \text { reduction, } p<0.001 \\
\text { CR: } 57 \text { vs. } 38 \%, p<0.001 \\
\text { PD: } 11 \text { vs. } 19 \%, p<0.001\end{array}$ & - & \\
\hline $\begin{array}{l}\text { Local control } \\
\text { (12-m cumulative } \\
\text { incidence) }\end{array}$ & - & - & $\begin{array}{l}\text { LC: } 86 \text { vs. } 69 \%, p \\
<0.001\end{array}$ & $\begin{array}{l}\text { LF: } 15.1 \text { vs. } 5.7 \%, p< \\
0.001 \text { ) } \\
\text { (only SRS) }\end{array}$ & $\begin{array}{l}\text { LF: } 12 \text { vs. } 19 \%, p=0.071 \\
\text { (concurrent) }\end{array}$ & $\begin{array}{l}\text { LF: } 15.1 \text { vs. } 5.7 \%, p< \\
0.001)\end{array}$ & \\
\hline Distant control & - & - & - & $\begin{array}{l}\text { DF: } 9.2 \text { vs. } 18.3 \%, p= \\
0.08\end{array}$ & $\begin{array}{l}\text { DF: } 48 \text { vs. } \\
49 \%, p=0.91 \\
\text { (concurrent) }\end{array}$ & - & \\
\hline Radiation necrosis & - & - & - & $\begin{array}{l}\text { RN: } 1.3 \text { vs. } 6.3 \%, p= \\
0.001\end{array}$ & $\begin{array}{l}\mathrm{RN}: 1.0 \text { vs. } 3.5 \%, p=0.134 \\
\text { (concurrent) }\end{array}$ & $\begin{array}{l}\text { RN: } 1.3 \text { vs. } 6.3 \%, p= \\
0.001\end{array}$ & \\
\hline
\end{tabular}

SRS, stereotactic radiosurgery; OS, overall survival; LC, local control; LF, local failure; $D C$, distant control; $D F$, distant failure; WBRT, whole-brain radiation therapy; RN, radiation necrosis; $C R$, complete response; PD, progressive disease; ORR, objective response rate; MBOR, median best objective response; BOR, best objective response; PR, partial response; MST, median survival time; HR, hazard ratio; HER-2, human epidermal growth factor receptor 2; mAb, monoclonal antibody. 


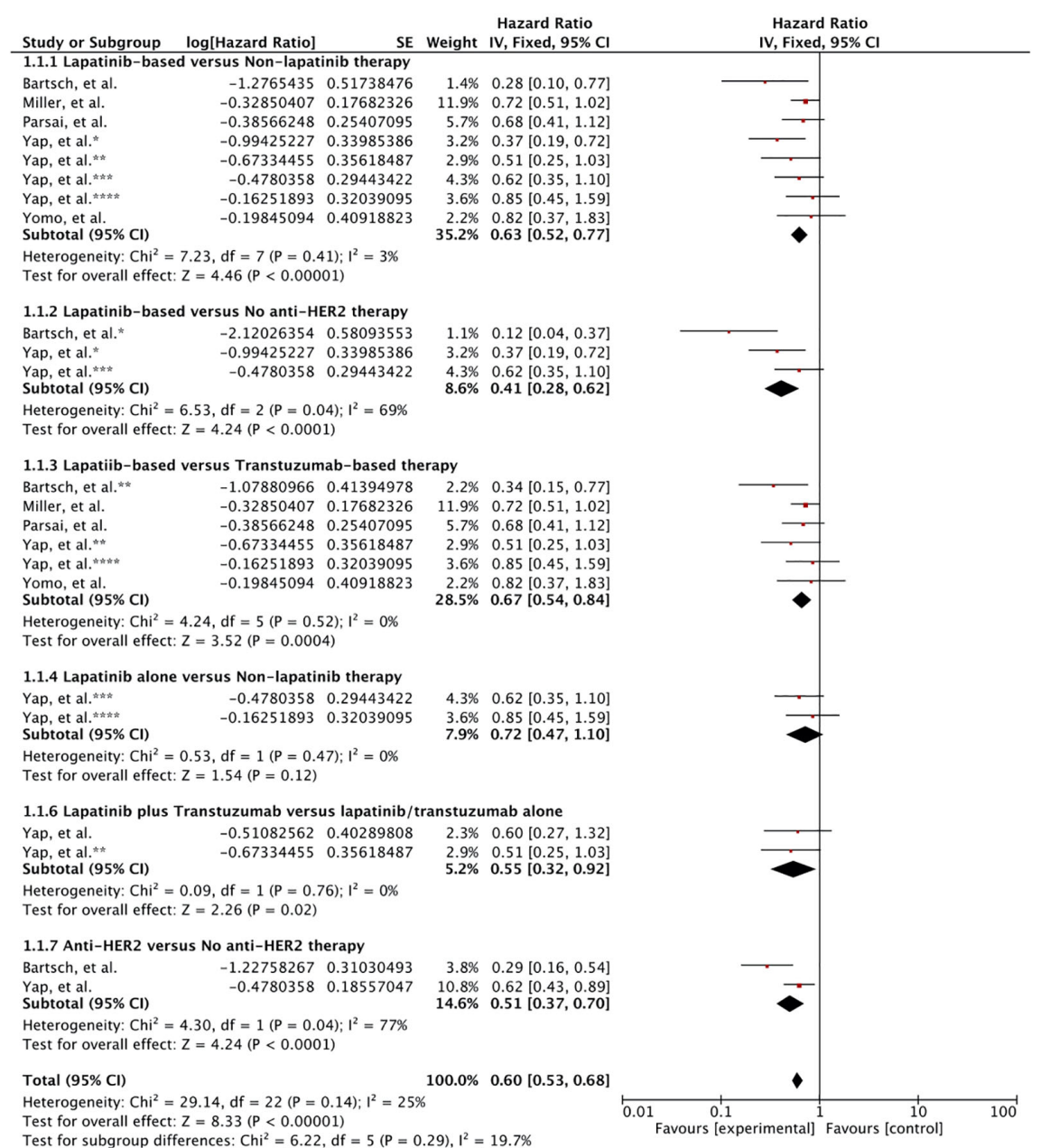

FIGURE 2 | Forest plot of meta-analysis of overall survival (OS) for treatment comparison (Lapatinib versus non-lapatinib-based therapy) in the management of brain metastases from HER-2 positive breast cancer.

trastuzumab alone $(\mathrm{p}=0.055)$ than lapatinib alone $(\mathrm{p}=020)$ as revealed by Yap et al. (40).

\section{Anti-HER2 vs. No Anti-HER2 Therapy}

At last, use of anti-HER2 therapy versus no anti-HER2 therapy was investigated. Overall, the use of anti-HER2 therapy comprising lapatinib and trastuzumab prolonged the survival for breast cancer patients expressing HER-2 with brain metastases $(0.51$ [0.37, 0.70], $\mathrm{p}=0.0001$ ) (Figure 2; Outcome 1.1.6) $(39,40)$. The result was based on outcomes from two studies $(39,40)$.

\section{Lapatinib Plus SRS Only as Local Therapy}

As a subgroup, we also evaluated the results involving SRS as the only therapy for BM and use of concurrent lapatinib. Shireen et, al. revealed a significant survival advantage for patients with any use of lapatinib (MST: 27.3 vs. 19.5 months, $\mathrm{p}=0.03$ ) (44). Patients in the study by Yomo et al. also had involved only SRS (41). Lapatinib-based therapy was not associated survival advantage (MST: 19.5 vs. 15.0 months, $\mathrm{p}=0.530$ ). However, low number of patients with high cross over was reported in this study. Though, Kim et al. revealed survival advantage with any use of lapatinib (MST: 33.3 vs. 23.6 months $(P=0.009)$ but concurrent use of lapatinib given with SRS $(n=18)$ compared to SRS alone $(n=66)$ was not associated with survival surge (MST: 40.4 vs. 25.1 months, $\mathrm{p}=0.155$ ) (43). Kim et al. also evaluated survival difference for patients using concurrent lapatinib versus any use of lapatinib within the group of 43 patients who had ever used lapatinib. There was no survival difference (40.4 vs. 33.3 months, $\mathrm{p}=0.775$ ).

\section{Objective Response Rate}

Only one study evaluated the objective response rate for treatment difference (43). Lesion-specific best objective response was superior in patients receiving concurrent lapatinib compared to SRS alone (100 vs. $70 \%$ reduction, $\mathrm{p}<$ 0.001). Complete response was $57 \%$ with concurrent lapatinib compared to $38 \%(\mathrm{p}<0.001)$ as well as lower progressive disease 
rate of 11 vs. $19 \%(\mathrm{p}<0.001)$. Median objective response rate at 6 -, and 12 -month were: 100 vs. $60 \%$ (p < 0.001), and 100 vs. $71 \%$ $(\mathrm{p}<0.001)$.

Kim et al. also investigated timing of lapatinib intervention and objective response. Overall response and best objective response were generally better when the intervention timing was closer to SRS induction. Median objective response was $100 \%$ when lapatinib was initiated concurrently $(\mathrm{n}=132$; CR: 57\%, PD: $11 \%$ ) or within 3 months of SRS induction ( $\mathrm{n}=150$; CR: $55 \%$, PD: $14 \%$ ). For patients receiving prior to SRS, objective response was $77 \%(\mathrm{n}=94$; CR: $40 \%$, PD: $7 \%)$, while it was $78 \%(\mathrm{n}=46$; CR: $43 \%$, PD: $15 \%$ ) for patients receiving it in 3 to 6 months and $85 \%$ ( $\mathrm{n}=75$; CR: $48 \%$, PD: $31 \%$ ) for patient using it after more than 6 months. Patients never using lapatinib reported the least objective response of $54 \%(n=111$; CR: $22 \%$, PD: $23 \%)$.

\section{Local Failure}

Local control was significantly increased with SRS plus lapatinib based on the meta-analysis of three studies (HR 0.47 [0.33, 0.66], $\mathrm{p}=0.0001)(41-43)$ (Figure 3). Two of these studies involved concurrent use of lapatinib with SRS indicating lapatinib given concurrently improves local control comparatively better.

\section{Distant Failure}

Distant failure was reported in two studies for treatment difference $(42,43)$. Comparatively lower rate of distant failure was observed with use of TKIs as 12-month cumulative incidence of DF was 9.2\% (95\% CI: $0.0-19.4 \%)$ with TKIs use in comparison to $18.3 \%$ (95\% CI: $14.8-21.8 \%$ ) without the use of TKIs. However, this difference was not significant $(\mathrm{p}=0.08)(42)$. In the study by Kim et al., no such difference was observed (43). 12-month cumulative incidence was 48\% (95\% CI: $28-68 \%$ ) with concurrent lapatinib as opposed to $49 \%$ (95\% CI: $40-58 \%)$ without concurrent lapatinib $(\mathrm{p}=0.91)$.

\section{Radiation Necrosis}

Two studies reported radiation necrosis rate revealing a lower rate for concurrent lapatinib and SRS $(42,43)$. In the study by Miller et al., concurrent HER2/lapatinib with SRS was associated with lower 12-month cumulative incidence of radiation necrosis ( 1.3 vs. $6.3 \%, p=0.001)(42)$. Shireen et al. further revealed the 6month ( 0.0 vs. $4.1 \%), 12$-month (1.3 vs. $6.3 \%)$, and 24 -month (1.9 vs. 8.2\%) cumulative incidences of radiation necrosis for concurrent lapatinib (44). Kim et al. also identified no association of concurrent lapatinib with increasing rates of radiation necrosis
(43). 12-month cumulative incidence rate of grade $2+\mathrm{RN}$ among patients with or without concurrent lapatinib was similar (1.0 vs. $3.5 \%, \mathrm{p}=0.134)$. Concurrent lapatinib was also not associated with increase rates of $\mathrm{RN}$ among larger lesions $(<1.5 \mathrm{~cm})$ despite an association between $\mathrm{RN}$ and increasing volume of lesion in the participants ( 0.0 vs. $4.5 \%, \mathrm{p}=0.39$ ).

\section{Publication Bias}

Funnel plot for overall survival was used for assessment of publication bias. All results were within the 95\% CI except for one comparison (Figure 4). In that comparison, lapatinibbased management was compared to patients managed with radiotherapy alone without any chemotherapy (39). Such drastic difference between the treatments made this comparison comparatively unique.

\section{DISCUSSION}

Management of brain metastases has been improving over the years with the introduction of newer targeting agents as well as advancements in the radiation and chemotherapy fields. SRS is being preferred over other local therapies or combined with other agents such as WBRT and surgery for treating BM including BC BM (52). Johnson et al. reviewed $737 \mathrm{BM}$ patients between 2000 and 2013 who had undergone upfront SRS for BMs, of which 167 had also received targeted agents concurrently or within 30 days of SRS (53). Overall, the use of targeted agents was associated with improved survival (65 vs. $30 \%$ at 12 months, $\mathrm{p}<0.0001$ ), local control ( 94 vs. $90 \%$ at 12 months, $\mathrm{p}=0.06$ ), distant brain control (32 vs. $18 \%$ at 12 months, $p=0.0001$ ), and freedom from WBRT (88 vs. $77 \%$ at 12 months, $\mathrm{p}=0.03$ ). On the hand, in a similar retrospective study, in which $1650 \mathrm{BM}$ patients treated with SRS plus/minus WBRT/surgery were investigated for concurrent use of targeted therapy (54). Use of targeted agents concurrently with SRS was not associated with survival on multivariate analysis (HR 0.90, 95\% CI $0.78-1.03, \mathrm{p}=0.11$ ). Nonetheless, breast cancer patients had achieved significant survival advantage with the use of concurrent targeted agents (trastuzumab and lapatinib) (18.2 vs. 13.8 months, $\mathrm{p}<0.01$ ). These outcomes suggest a rise in the use of concurrent targeted agents with radiation therapy. Here we have reviewed literature for comparative evidence regarding the combined use of radiation therapy and lapatinib for HER-2 positive breast cancer patients with brain metastases.

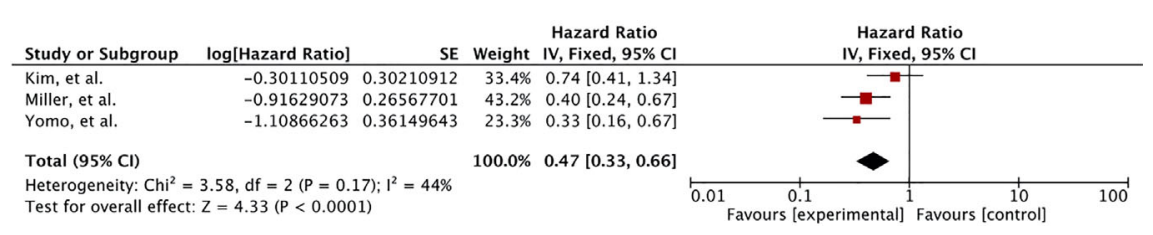

FIGURE 3 | Forest plot of meta-analysis of local control (LC) for treatment comparison (Lapatinib plus SRS versus SRS alone) in the management of brain metastases from HER-2 positive breast cancer. 


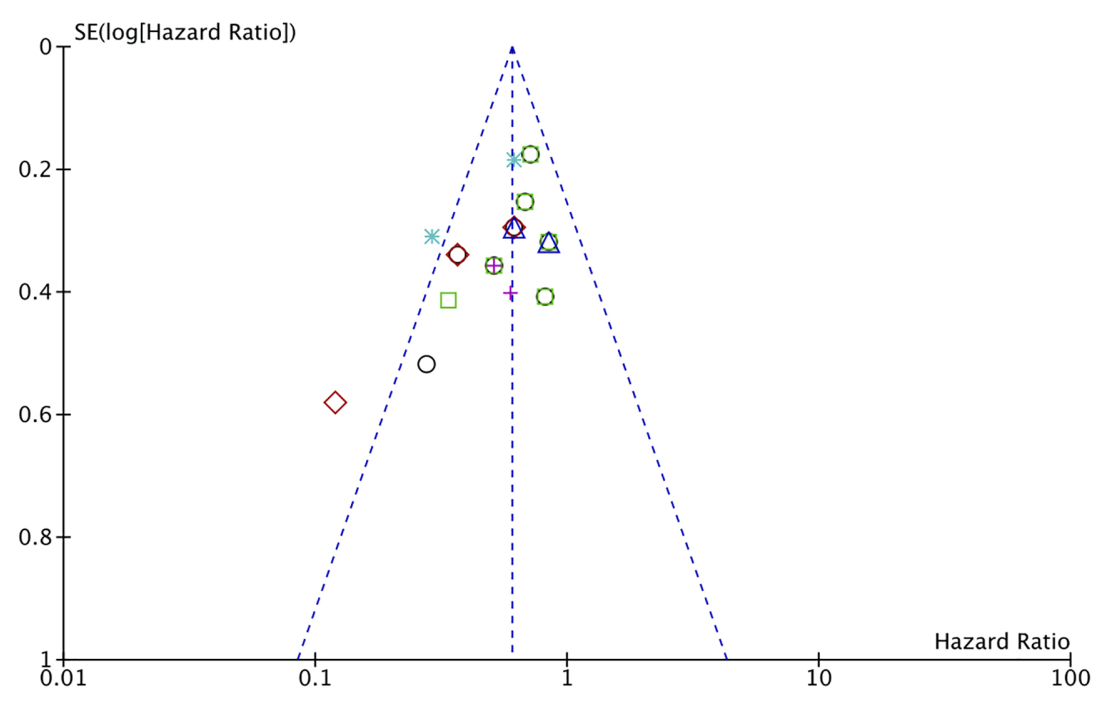

Subgroups

$\checkmark$ Lapatinib-based versus No anti-HER2 therapy

$\square$ Lapatiib-based versus Transtuzumab-based therapy

$\triangle$ Lapatinib alone versus Non-lapatinib therapy

+ Lapatinib plus Transtuzumab versus lapatinib/transtuzumab alone

* Anti-HER2 versus No anti-HER2 therapy

FIGURE 4 | Funnel plot of publication bias assessment for overall survival.

Our meta-analysis reveals a significant increase in overall survival for HER-2 positive patients with brain metastases receiving lapatinib-based management. In the non-lapatinib based therapy, majority of the patients were exposed to trastuzumab. Lapatinib use was associated with additive survival advantage against patients not receiving any antiHER2 therapy at all. Likewise, survival benefit was maintained in comparison to patients receiving trastuzumab-based management. This result is in line with the data from Metro et al. study (55). HER-2 positive BC patients with brain metastases treated with lapatinib plus capecitabine were associated with significantly higher median survival as opposed to trastuzumab-based therapies (MST: 27.9 vs. 16.7 months, $\mathrm{p}=$ $0.01)$. Radiotherapy was also delivered to majority $(26 / 30)$ of patients but the duration between radiotherapy and LC initiation was equal to or greater than two months. In a study by Anatolian Society of Medical Oncology (ASMO), lapatinib plus capecitabine $(n=46)$ was revealed with significantly improved survival (MST: 19.1 vs. 12.0 months, $\mathrm{p}=0.039$ ) compared to patients receiving trastuzumab-based therapy $(n=65)$ for BM management (56). In this study, only a portion of patients had received radiosurgery $(n=33 ; 14 / 19)$ and neurosurgery $(n=16$; 2/14). Similarly, a case report of 45 years old HER-2 BC patients with BM treated with RT followed by lapatinib plus capecitabine (with capecitabine for 10 months and with letrozole for 3 months) had also achieved a longer survival of 45 months (57). In this case, lapatinib plus capecitabine was re-inducted after brain relapse indicating successful reinduction of lapatinib in such patients.
Lapatinib alone after $\mathrm{BM}$, on the other hand, was not associated with increased survival compared to no anti-HER2 therapy as well as trastuzumab alone. Even though, the result is based only on one study, it may indicate lapatinib inability to control extracranial disease. As it has been demonstrated in the study by Miller et al. that lapatinib was able to extend survival by 7 months for patients with extracranial disease (MST: 20 vs. 13 months, $\mathrm{p}=0.14$ ) as compared to 16 months for patients without extracranial disease (MST: 39 vs. 23 months, $\mathrm{p}=0.05$ ) (42). Instead, trastuzumab is associated with increased incidence of $\mathrm{BM}$ and neurologic cause of death in HER2 positive BC patients despite prolonging survival $(30-35,58)$. It has been suggested that better extracranial control with trastuzumab leads to prolong survival, hence, more patients are surviving to have $\mathrm{BM}$, and it may also suggest trastuzumab ineffectiveness in the brain leading to more neurologic deaths (59). This fact could also be reflected in our results as combining the two were superior to each treatment alone particularly the trastuzumab in prolonging survival. Though, the majority of the patients in combined group received both agents sequentially $(n=22 / 28)$. The combination had also been shown in RCTs to prolong event-free survival and overall survival in comparison to each alone in HER-2 positive $\mathrm{BC}$ patients without $\mathrm{BM}(60,61)$. In fact, pathological complete responses in combined group were higher as compared to each group alone (62-66). Rates of pCR were the lowest in lapatinib group $(n=154 / 414)$ compared to trastuzumab alone $(n=183 / 439)$ suggesting lower systemic activity of lapatinib (base/Bonn) (OR $0.85[0.64,1.14], \mathrm{p}=0.29)(62-66)$. The difference trended towards significance when data was restricted to 3 studies $(\mathrm{L}=53 / 205$ 
vs. $\mathrm{T}=81 / 227$; OR $0.69[0.44,1.06], \mathrm{p}=0.09)(62,63,66)$. Moreover, in head to head trials (TC vs. LC), contradicting results were obtained $(67,68)$. WJOG6110B/ELTOP trial failed to show any significant difference between the two treatments in patients pretreated with trastuzumab (67). CEREBEL trial, however, showed significant PFS (HR 1.30; 1.04-1.64, $\mathrm{p}=0.021)$ and OS (HR 1.34; 0.95-1.90, $\mathrm{p}=0.095$ ) survival advantage for trastuzumab plus capecitabine lapatinib compared to lapatinib plus capecitabine (68). Difference in PFS was further increased when patients without any previous exposure to trastuzumab was considered (HR 1.70; 1.15-2.50). These outcomes suggest that lapatinib, though have intracranial activity, may still require trastuzumab to control the extracranial disease and vice versa in order to achieve best outcomes.

In our study, SRS alone was used in all the studies but WBRT, despite being used in only three studies, was the leading local therapy for BM according to the number of patients (39-44). Three studies had involved only SRS and 2 studies had used concurrent lapatinib with SRS $(41,43,44)$. Administration of lapatinib with SRS or within five biological half-lives from the date of SRS was defined as concurrent lapatinib. Half-life elimination of lapatinib is 24 hours creating a window of 5 days before or after SRS for lapatinib induction (43). Ever use of lapatinib with SRS was significantly associated with survival as reported in two studies $(43,44)$. However, concurrent use was not revealed to have any survival advantage as demonstrated by Kim et al. (43). Even though, a trend towards significance in local control $(p=0.071)$ and significant higher rates of complete responses (35 vs. $11 \%, P=0.008$ ) were revealed in their study with concurrent lapatinib (43). Failure to report SRS advantage may come from the fact that number of patients were few $(n=$ 18 ) in the concurrent lapatinib group (43). Meta-analysis of local control rates also revealed a significantly increased brain local control with application of SRS and lapatinib (41-43). This suggests survival advantage with SRS in combination with lapatinib could signify synergism between the two agents. As lapatinib is a small molecule and is assumed to cross BBB, however, its brain distribution was shown to be restricted by BBB $(69,70)$. Moreover, lapatinib alone has only obtained moderate intracranial responses $(2.6-6 \%)(27,37)$. Inability of lapatinib to affect distant control in the study of Kim, et al. also suggest its limited access to the brain as observed in case of other TKIs; VEGFR TKIs in RCC BM, and BRAF/MEK inhibitors in melanoma $(43,53,71-74)$. These outcomes suggest that lapatinib, though a small molecule, is restricted partially by BBB. SRS is hypothesized to disrupt BBB locally thereby increasing the lapatinib delivery to brain $(75,76)$. Hence, resulting in synergistic activity of both agents and resulting in local control improvement as is observed with other TKIs (VEGR TKI for RCC and BRAF/MEK inhibitors for Melanoma) $(53,71,73,77-79)$. Moreover, it can also be observed in the results of Kim et al., demonstrating a significant increase in complete responses with concurrent delivery of lapatinib with SRS (35 vs. $11 \%, P=0.008$ ) (43). This response rate is comparatively better in comparison to other studies that lacked the use of SRS or any local therapy in addition to lapatinib. Objective response rates between
$33.3 \%$ to $57 \%$ was revealed for lapatinib plus capecitabine management $(56,80,81)$. LANDSCAPE phase trial had reported only two cases of complete response [ORR: 24/42 (57\%); CR: 2; PR: 22; SD: 15; PD: 3], Shawky, H. and H. Tawfik reported 0 cases [ORR:7/21 (33.3\%); CR: 0; PR: 7], and Kaplan et al. also reported 0 cases of complete response [ORR: 14/38 (36.8\%), CR: 0; PR: 14; SD:12; PD: 12] (56, 80, 81). Moreover, SRS use in the study by Kaplan et al. was significant for overall survival advantage (MST: 20.3 vs. 11 months, $\mathrm{p}=0.007$ ) (56). These outcomes emphasize the use of lapatinib in combination with SRS in order to allow more time and dose for lapatinib activity in the brain, and obtain synergistic activity.

Kim et al. revealed no difference in distant control for SRS plus lapatinib compared to SRS alone (43). This result in line with the data reported in several retrospective studies that involved other TKIs use for RCC (VEGFR TKIs/mTORi) and melanoma BMs (BRAFi/MEKi) (71-74). In contrast, patients with breast cancer (HER2+/HER-) had obtained better distant control with the use of targeted agents with SRS in the study by Johnson et al. (median 10 vs. 5 months, $p=0.002$ ) (53). Kotecha et al. had also shown improvement in distant control with the use of BRAFi plus SRS (12-m CI of DF: 68 vs. 95\%, p =0.03) (82). Improved distant control with use of TKIs was revealed by Miller et al. (12-month cumulative incidence of distant failure: 9.2 vs. $18.3 \%, \mathrm{p}=0.08$ ) for patients with upfront local therapy with/ without WBRT (42). The 12-months cumulative incidences were $24.8 \%$ for luminal B (95\% CI: $17.0-32.5 \%)$, and $17.3 \%$ for HER2 + (95\% CI: 9.5-25.1\%). For patients receiving SRS as upfront therapy without WBRT, the 12-month cumulative incidence of distant failure increased to $38 \%$ for luminal B (95\% CI: $13-62 \%$ ), and 53\% for HER21 (95\% CI: $26-81 \%$ ). Miller et al. also identified that the use of WBRT significantly reduced the 12-month cumulative incidences of distant failure (12m-CI DF: 17.4 vs. $28.4 \%, \mathrm{p}<0.01)$ for all patients that also included triple negative and luminal $\mathrm{A}$ in addition to luminal $\mathrm{B}$ and HER-2 positive BC patients (42). Similarly, significant distant control was reported for VEGFR TKIs and mTOR inhibitors in RCC BM patients (12-mCI: 16.9 vs. $10.5 \%, \mathrm{p}=$ 0.003 ) but significance was lost when upfront WBRT was excluded from analysis ( 26.8 vs. $24.4 \%, \mathrm{p}=0.150)(83)$. These outcomes highlight the role of WBRT in enhancing the response rate of lapatinib and decreasing the distant failure rates. Moreover, WBRT plus lapatinib was associated with increased intracranial response rates in a phase I study (79\%), indicating better local control as well (38). Therefore, despite the increasing trend of SRS as the sole treatment of BM for this group of patients, the role of WBRT still can't be ruled out and would need further evaluation given the safety concerns with its use.

Lapatinib is associated with a number of systemic and neurologic side effects such as diarrhea, fatigue, nausea, vomiting, and rash etcetera $(27,37)$. However, none systemic side effects were reported in all the studies (39-44). Three studies reported radiation necrosis rated for treatment difference (42-44). Miller et al. reported a decrease in $\mathrm{RN}$ rates with lapatinib plus SRS use while Kim et al. revealed a lower rate of $\mathrm{RN}$ in concurrent lapatinib group as compared to SRS alone $(42,43)$. Radiation necrosis is a 
dose-limiting toxicity of SRS occurring in 5 to $10 \%$ of patients (54). In a study of nearly 2000 patients undergoing SRS, 15\% had experienced $\mathrm{RN}$, and HER-2 amplification was identified as an associated factor (HR 2.05, $\mathrm{p}=0.02$ ) along with other histology such as renal, lung adenocarcinoma, ALK/BRAF mutational status (84). In their study, the use of HER2 antibodies (5.9 vs. $7.9 \%, \mathrm{p}=$ 0.50 ) or lapatinib ( 0 vs. $9 \%, \mathrm{p}<0.01$ ) within 30 days of SRS were not associated with increased 12-month cumulative incidence of $\mathrm{RN}$ in the HER2 amplified population. It maybe hypothesized that lapatinib may lower the number of HER-2 oncoproteins thereby reducing the radiosensitivity to SRS that is observed with mutated oncoproteins (ALK/EGFR/BRAF). In line with these data, concurrent lapatinib was not associated with any increased 12month cumulative incidences of RN in study of Kim et al. (12.5 vs. $7.7 \%, \mathrm{p}=0.24)(54)$.

Our study is limited by retrospective nature of the included studies (39-44). Retrospective studies are subject to confounding and tend to have selection bias, recall bias, and misclassification bias (85). These outcomes were also reflected in the results of quality assessment. Only 6 studies were available for inclusion (39-44). Some of the results in our study were also based on outcomes from one or two studies. Moreover, some studies had very limited number of participants $(39,41)$. Yomo et al. study is limited due to its low number of patients and high cross over (41). Of the total 40 patients, 12 patients from lapatinib based therapy had switched from trastuzumab and later 6 patients had cross over to trastuzumab after using lapatinib. This cross over could have confounded the survival outcome as no survival difference was achieved despite significant brain local control with lapatinib-based therapy. Bartsch et al. study had very few patients receiving lapatinib (39). Its comparison to patients with radiotherapy alone yielded a very low hazard ratio and high standard error due the huge difference between the survival rate. This result has caused the heterogeneity among some results.

\section{Future Perspective}

Lapatinib is the first proven HER-2 targeting tyrosine kinase inhibitor (10). As monotherapy, it has only shown a mild $2.6 \%$ to $6 \%$ intracranial response $(27,37)$. In combination with capecitabine response rate was increased between $20 \%$ to $57 \%$ $(37,80)$. Response rate was further enhanced in combination with WBRT $(79 \%)$, and SRS $(75 \%)(38,43)$. Lower response rate as monotherapy suggests low bioavailability of the drug in the target tissue. Preclinical and clinical evidence have suggested $\mathrm{BBB}$ restriction of lapatinib $(69,70,86)$. Two members of ATPbinding cassette $(\mathrm{ABC})$ family of transporters namely $\mathrm{P}$ glycoprotein (P-gp; ABCB1) and breast cancer resistance protein (BCRP; ABCG2) have been implicated in the restriction of several drugs including lapatinib (87-91). Elacridar, an ABCB1 and ABCG2 blocker, was shown to enhance the penetration of lapatinib into the CSF and brain tissue (92). It's an area that could further enhance the effectivity of lapatinib in the brain. Our results also suggest that combination of lapatinib and trastuzumab enhances the outcome compared to each treatment alone that has also been demonstrated in the case of HER-2 + MBC patients (60-66). In the phase I trial, impressive 79\% response was achieved through concurrent use of both agents with WBRT
(38). Hence, a combo might further enhance the survival outcome for BCBM patients given the safety concerns are alleviated. On the other hand, SRS has not been tested yet for feasibility with lapatinib and trastuzumab combination. Results of a clinical trial are awaiting in this regard which has combined WBRT or SRS with or without lapatinib in BCBM patients (NCT01622868). EMILIA trial has shown superior efficacy for T-DMI compared to lapatinib plus capecitabine in MBC patients (93). However, recent data suggests the combination of T-DMI and SRS was associated with an increased brain toxicity limiting its use for BCBM patients $(94,95)$. Therefore, Lapatinib in combination with SRS/WBRT with caution should be evaluated for these patients for further improvement in the survival and quality of life. Nonetheless, overall research regarding the treatment of BCBM patients have not been rigorous. Fares et al. identified several factors impeding the BCBM research such as low number of trials, low accrual numbers, and lack of diversity (96). In addition, these hurdles would also need to be overcome through proper selection of treatment regimens to be investigated. Systematic reviews and meta-analysis such as this could facilitate such selection and assist in optimizing the BCBM research.

\section{CONCLUSIONS}

Improvement in survival is observed for HER-2 positive BC patients with BMs being treated with lapatinib-based management. Local brain control was observed with the combination of SRS and lapatinib. Concurrent lapatinib may have better effect as increased intracranial responses were also witnessed. WBRT given in combination with SRS was also shown to have an impact on distant brain control, suggesting a role for WBRT in this group of patients. Lapatinib with SRS was revealed to have lower risk for radiation necrosis in comparison to SRS alone.

\section{DATA AVAILABILITY STATEMENT}

The original contributions presented in the study are included in the article/supplementary material. Further inquiries can be directed to the corresponding author.

\section{AUTHOR CONTRIBUTIONS}

All authors have contributed equally. All authors contributed to the article and approved the submitted version.

\section{FUNDING}

This work was supported by the Natural Science Foundation of Shenzhen (no. JCYJ20170307095828424), Shenzhen Health and Family Planning System Research Project (no. SZBC2017024), and the technical research and cultivation project for the youth of Shenzhen People's Hospital (no. SYKYPY2019029). 


\section{REFERENCES}

1. Siegel RL, Miller KD, Jemal A. Cancer statistics, 2020. CA Cancer J Clin (2020) 70(1):7-30. doi: 10.3322/caac. 21590

2. American Cancer Society. Cancer facts \& Figures (2020). Available at: https:// www.cancer.org/research/cancer-facts-statistics/all-cancer-facts-figures/ cancer-facts-figures-2020.html (Accessed March 20, 2020).

3. Nounou MI, ElAmrawy F, Ahmed N, Abdelraouf K, Goda S, Syed-ShaQhattal H. Breast Cancer: Conventional Diagnosis and Treatment Modalities and Recent Patents and Technologies. Breast Cancer (Auckl) (2015) 9(Suppl 2):17-34. doi: 10.4137/BCBCR.S29420

4. Sharma GN, Dave R, Sanadya J, Sharma P, Sharma KK. Various types and management of breast cancer: an overview. J Adv Pharm Technol Res (2010) 1 (2):109-26.

5. Dhankhar R, Vyas SP, Jain AK, Arora S, Rath G, Goyal AK. Advances in novel drug delivery strategies for breast cancer therapy. Artif Cells Blood Substit Immobil Biotechnol (2010) 38(5):230-49. doi: 10.3109/10731199.2010.494578

6. Tong CWS, Wu M, Cho WCS, To KKW. Recent Advances in the Treatment of Breast Cancer. Front Oncol (2018) 8:227. doi: 10.3389/fonc.2018.00227

7. Logan GJ, Dabbs DJ, Lucas PC, Jankowitz RC, Brown DD, Clark BZ, et al. Molecular drivers of lobular carcinoma in situ. Breast Cancer Res (2015) 17:76. doi: 10.1186/s13058-015-0580-5

8. Mener AS, Aggarwal A. Advances in Targeted Therapy for Breast Cancer. Fed Pract (2015) 32(Suppl 4):46S-9S.

9. Baselga J. Phase I and II clinical trials of trastuzumab. Ann Oncol Off J Eur Soc Med Oncol (2001) 12 Suppl 1:S49-55. doi: 10.1093/annonc/12.suppl_1.s49

10. Ryan Q, Ibrahim A, Cohen MH, Johnson J, Ko CW, Sridhara R, et al. FDA drug approval summary: lapatinib in combination with capecitabine for previously treated metastatic breast cancer that overexpresses HER-2. Oncol (2008) 13(10):1114-9. doi: 10.1634/theoncologist.2008-0816

11. Miles J, White Y. Neratinib for the Treatment of Early-Stage HER2-Positive Breast Cancer. J Adv Pract Oncol (2018) 9(7):750-4. doi: 10.6004/ jadpro.2018.9.7.6

12. Murthy RK, Loi S, Okines A, Paplomata E, Hamilton E, Hurvitz SA, et al. Tucatinib, Trastuzumab, and Capecitabine for HER2-Positive Metastatic Breast Cancer. New Engl J Med (2019) 382(7):597-609. doi: 10.1056/ NEJMoa1914609

13. McCart Reed AE, Kutasovic JR, Lakhani SR, Simpson PT. Invasive lobular carcinoma of the breast: morphology, biomarkers and 'omics. Breast Cancer Res (2015) 17(1):12. doi: 10.1186/s13058-015-0519-x

14. Vorobiof DA. Recent advances in the medical treatment of breast cancer. F1000Res (2016) 5:2786-. doi: 10.12688/f1000research.9619.1

15. Eichler AF, Loeffler JS. Multidisciplinary management of brain metastases. Oncol (2007) 12(7):884-98. doi: 10.1634/theoncologist.12-7-884

16. Lippitz B, Lindquist C, Paddick I, Peterson D, O’Neill K, Beaney R. Stereotactic radiosurgery in the treatment of brain metastases: the current evidence. Cancer Treat Rev (2014) 40(1):48-59. doi: 10.1016/j.ctrv.2013. 05.002

17. Kühnöl J, Kühnöl C, Vordermark D. Radiotherapy of brain metastases from breast cancer: Treatment results and prognostic factors. Oncol Lett (2016) 11 (5):3223-7. doi: 10.3892/ol.2016.4349

18. Sperduto PW, Chao ST, Sneed PK, Luo X, Suh J, Roberge D, et al. Diagnosisspecific prognostic factors, indexes, and treatment outcomes for patients with newly diagnosed brain metastases: a multi-institutional analysis of 4,259 patients. Int J Radiat Oncol Biol Phys (2010) 77(3):655-61. doi: 10.1016/ j.ijrobp.2009.08.025

19. Kondziolka D, Kano H, Harrison GL, Yang HC, Liew DN, Niranjan A, et al. Stereotactic radiosurgery as primary and salvage treatment for brain metastases from breast cancer. Clinical article. J Neurosurg (2011) 114 (3):792-800. doi: 10.3171/2010.8.Jns10461

20. Muacevic A, Kreth FW, Tonn J-C, Wowra B. Stereotactic radiosurgery for multiple brain metastases from breast carcinoma. Cancer (2004) 100(8):170511. doi: $10.1002 /$ cncr.20167

21. Xu Z, Marko NF, Chao ST, Angelov L, Vogelbaum MA, Suh JH, et al. Relationship between HER2 status and prognosis in women with brain metastases from breast cancer. Int J Radiat Oncol Biol Phys (2012) 82(5): e739-47. doi: 10.1016/j.ijrobp.2011.06.1968
22. Xu Z, Schlesinger D, Toulmin S, Rich T, Sheehan J. Impact of triple-negative phenotype on prognosis of patients with breast cancer brain metastases. Int J Radiat Oncol Biol Physics (2012) 84(3):612-8. doi: 10.1016/j.ijrobp.2011.12.054

23. Sperduto PW, Kased N, Roberge D, Chao ST, Shanley R, Luo X, et al. The effect of tumor subtype on the time from primary diagnosis to development of brain metastases and survival in patients with breast cancer. J Neurooncol (2013) 112(3):467-72. doi: 10.1007/s11060-013-1083-9

24. Cho E, Rubinstein L, Stevenson P, Gooley T, Philips M, Halasz LM, et al. The use of stereotactic radiosurgery for brain metastases from breast cancer: who benefits most? Breast Cancer Res Treat (2015) 149(3):743-9. doi: 10.1007/ s10549-014-3242-x

25. Tsutsui S, Ohno S, Murakami S, Hachitanda Y, Oda S. Prognostic value of epidermal growth factor receptor (EGFR) and its relationship to the estrogen receptor status in 1029 patients with breast cancer. Breast Cancer Res Treat (2002) 71(1):67-75. doi: 10.1023/a:1013397232011

26. Jiang H, Rugo HS. Human epidermal growth factor receptor 2 positive (HER2+) metastatic breast cancer: how the latest results are improving therapeutic options. Ther Adv Med Oncol (2015) 7(6):321-39. doi: 10.1177/1758834 015599389

27. Lin NU, Carey LA, Liu MC, Younger J, Come SE, Ewend M, et al. Phase II trial of lapatinib for brain metastases in patients with human epidermal growth factor receptor 2-positive breast cancer. J Clin Oncol Off J Am Soc Clin Oncol (2008) 26(12):1993-9. doi: 10.1200/jco.2007.12.3588

28. Slamon DJ, Clark GM, Wong SG, Levin WJ, Ullrich A, McGuire WL. Human breast cancer: correlation of relapse and survival with amplification of the HER-2/neu oncogene. Sci (N Y NY) (1987) 235(4785):177-82. doi: 10.1126/ science. 3798106

29. Seshadri R, Firgaira FA, Horsfall DJ, McCaul K, Setlur V, Kitchen P. Clinical significance of HER-2/neu oncogene amplification in primary breast cancer. The South Australian Breast Cancer Study Group. J Clin Oncol Off J Am Soc Clin Oncol (1993) 11(10):1936-42. doi: 10.1200/jco.1993.11.10.1936

30. Kirsch DG, Ledezma CJ, Mathews CS, Bhan AK, Ancukiewicz M, Hochberg $\mathrm{FH}$, et al. Survival after brain metastases from breast cancer in the trastuzumab era. J Clin Oncol Off J Am Soc Clin Oncol (2005) 23(9):2114-6; author reply 6-7. doi: 10.1200/jco.2005.05.249

31. Dawood S, Broglio K, Esteva FJ, Ibrahim NK, Kau SW, Islam R, et al. Defining prognosis for women with breast cancer and CNS metastases by HER2 status. Ann Oncol Off J Eur Soc Med Oncol (2008) 19(7):1242-8. doi: 10.1093/ annonc/mdn036

32. Bendell JC, Domchek SM, Burstein HJ, Harris L, Younger J, Kuter I, et al. Central nervous system metastases in women who receive trastuzumab-based therapy for metastatic breast carcinoma. Cancer (2003) 97(12):2972-7. doi: $10.1002 / \mathrm{cncr} .11436$

33. Clayton AJ, Danson S, Jolly S, Ryder WD, Burt PA, Stewart AL, et al. Incidence of cerebral metastases in patients treated with trastuzumab for metastatic breast cancer. Br J Cancer (2004) 91(4):639-43. doi: 10.1038/ sj.bjc. 6601970

34. Lower EE, Drosick DR, Blau R, Brennan L, Danneman W, Hawley DK. Increased rate of brain metastasis with trastuzumab therapy not associated with impaired survival. Clin Breast Cancer (2003) 4(2):114-9. doi: 10.3816/ cbc.2003.n.016

35. Burton A. High incidence of brain metastases with trastuzumab treatment. Lancet Oncol (2004) 5(9):523. doi: 10.1016/S1470-2045(04)01558-X

36. Cameron D, Casey M, Press M, Lindquist D, Pienkowski T, Romieu CG, et al. A phase III randomized comparison of lapatinib plus capecitabine versus capecitabine alone in women with advanced breast cancer that has progressed on trastuzumab: updated efficacy and biomarker analyses. Breast Cancer Res Treat (2008) 112(3):533-43. doi: 10.1007/s10549-007-9885-0

37. Lin NU, Diéras V, Paul D, Lossignol D, Christodoulou C, Stemmler HJ, et al. Multicenter phase II study of lapatinib in patients with brain metastases from HER2-positive breast cancer. Clin Cancer Res Off J Am Assoc Cancer Res (2009) 15(4):1452-9. doi: 10.1158/1078-0432.Ccr-08-1080

38. Lin NU, Freedman RA, Ramakrishna N, Younger J, Storniolo AM, Bellon JR, et al. A phase I study of lapatinib with whole brain radiotherapy in patients with Human Epidermal Growth Factor Receptor 2 (HER2)-positive breast cancer brain metastases. Breast Cancer Res Treat (2013) 142(2):405-14. doi: 10.1007/s10549-013-2754-0 
39. Bartsch R, Berghoff A, Pluschnig U, Bago-Horvath Z, Dubsky P, Rottenfusser A, et al. Impact of anti-HER2 therapy on overall survival in HER2-overexpressing breast cancer patients with brain metastases. Br J Cancer (2012) 106(1):25-31. doi: 10.1038/bjc.2011.531

40. Yap YS, Cornelio GH, Devi BC, Khorprasert C, Kim SB, Kim TY, et al. Brain metastases in Asian HER2-positive breast cancer patients: anti-HER2 treatments and their impact on survival. Br J Cancer (2012) 107(7):1075-82. doi: 10.1038/ bjc. 2012.346

41. Yomo S, Hayashi M, Cho N. Impacts of HER2-overexpression and molecular targeting therapy on the efficacy of stereotactic radiosurgery for brain metastases from breast cancer. J Neurooncol (2013) 112(2):199-207. doi: 10.1007/s11060-013-1046-1

42. Miller JA, Kotecha R, Ahluwalia MS, Mohammadi AM, Chao ST, Barnett GH, et al. Overall survival and the response to radiotherapy among molecular subtypes of breast cancer brain metastases treated with targeted therapies. Cancer (2017) 123(12):2283-93. doi: 10.1002/cncr.30616

43. Kim JM, Miller JA, Kotecha R, Chao ST, Ahluwalia MS, Peereboom DM, et al. Stereotactic radiosurgery with concurrent HER2-directed therapy is associated with improved objective response for breast cancer brain metastasis. Neuro Oncol (2019) 21(5):659-68. doi: 10.1093/neuonc/noz006

44. Shireen P, Jacob AM, Aditya J, Samuel TC, Rupesh K, Alireza MM, et al. Stereotactic radiosurgery with concurrent lapatinib is associated with improved local control for HER2-positive breast cancer brain metastases. J Neurosurg JNS (2019) 132(2):503-11. doi: 10.3171/2018.10.JNS182340

45. Moher D, Liberati A, Tetzlaff J, Altman DG. Preferred reporting items for systematic reviews and meta-analyses: the PRISMA statement. J Clin Epidemiol (2009) 62(10):1006-12. doi: 10.1016/j.jclinepi.2009.06.005

46. Downs SH, Black N. The feasibility of creating a checklist for the assessment of the methodological quality both of randomised and non-randomised studies of health care interventions. JEpidemiol Community Health (1998) 52(6):37784. doi: $10.1136 /$ jech.52.6.377

47. Simic M, Hinman RS, Wrigley TV, Bennell KL, Hunt MA. Gait modification strategies for altering medial knee joint load: a systematic review. Arthritis Care Res (Hoboken) (2011) 63(3):405-26. doi: 10.1002/acr.20380

48. Tierney JF, Stewart LA, Ghersi D, Burdett S, Sydes MR. Practical methods for incorporating summary time-to-event data into meta-analysis. Trials (2007) 8:16-. doi: 10.1186/1745-6215-8-16

49. Review Manager (RevMan). [Computer program]. Version 5.3. Copenhagen: The Nordic Cochrane Centre, The Cochrane Collaboration (2014).

50. Review Manager Web (RevMan Web). (2019). Available at revman. cochrane.org.

51. Higgins JPT, Thompson SG, Deeks JJ, Altman DG. Measuring inconsistency in meta-analyses. BMJ (Clin Res ed) (2003) 327(7414):557-60. doi: 10.1136/ bmj.327.7414.557

52. Barbour AB, Jacobs CD, Williamson H, Floyd SR, Suneja G, Torok JA, et al. Radiation Therapy Practice Patterns for Brain Metastases in the United States in the Stereotactic Radiosurgery Era. Adv Radiat Oncol (2020) 5(1):43-52. doi: 10.1016/j.adro.2019.07.012

53. Johnson AG, Ruiz J, Hughes R, Page BR, Isom S, Lucas JT, et al. Impact of systemic targeted agents on the clinical outcomes of patients with brain metastases. Oncotarget (2015) 6(22):18945-55. doi: 10.18632/oncotarget.4153

54. Kim JM, Miller JA, Kotecha R, Xiao R, Juloori A, Ward MC, et al. The risk of radiation necrosis following stereotactic radiosurgery with concurrent systemic therapies. J Neurooncol (2017) 133(2):357-68. doi: 10.1007/s11060-017-2442-8

55. Metro G, Foglietta J, Russillo M, Stocchi L, Vidiri A, Giannarelli D, et al. Clinical outcome of patients with brain metastases from HER2-positive breast cancer treated with lapatinib and capecitabine. Ann Oncol Off J Eur Soc Med Oncol (2011) 22(3):625-30. doi: 10.1093/annonc/mdq434

56. Kaplan MA, Isikdogan A, Koca D, Kucukoner M, Gumusay O, Yildiz R, et al. Clinical outcomes in patients who received lapatinib plus capecitabine combination therapy for HER2-positive breast cancer with brain metastasis and a comparison of survival with those who received trastuzumab-based therapy: a study by the Anatolian Society of Medical Oncology. Breast Cancer (2014) 21(6):677-83. doi: 10.1007/s12282-013-0441-y

57. Karagöz B, Özgün A, Emirzeoğlu L, Tunçel T, Çelik S, Bilgi O, et al. Long-term Survival after Lapatinib Rechallenge in Isolated Brain Metastasis of HER2positive Breast Cancer. J Breast Health (2015) 11(1):48-51. doi: 10.5152/ tjbh.2014.2009
58. Musolino A, Ciccolallo L, Panebianco M, Fontana E, Zanoni D, Bozzetti C, et al. Multifactorial central nervous system recurrence susceptibility in patients with HER2-positive breast cancer: epidemiological and clinical data from a population-based cancer registry study. Cancer (2011) 117(9):1837-46. doi: 10.1002/cncr.25771

59. Park YH, Park MJ, Ji SH, Yi SY, Lim DH, Nam DH, et al. Trastuzumab treatment improves brain metastasis outcomes through control and durable prolongation of systemic extracranial disease in HER2-overexpressing breast cancer patients. Br J Cancer (2009) 100(6):894-900. doi: 10.1038/sj.bjc. 6604941

60. de Azambuja E, Holmes AP, Piccart-Gebhart M, Holmes E, Di Cosimo S, Swaby RF, et al. Lapatinib with trastuzumab for HER2-positive early breast cancer (NeoALTTO): survival outcomes of a randomised, open-label, multicentre, phase 3 trial and their association with pathological complete response. Lancet Oncol (2014) 15(10):1137-46. doi: 10.1016/s1470-2045(14)70320-1

61. Blackwell KL, Burstein HJ, Storniolo AM, Rugo HS, Sledge G, Aktan G, et al. Overall survival benefit with lapatinib in combination with trastuzumab for patients with human epidermal growth factor receptor 2-positive metastatic breast cancer: final results from the EGF104900 Study. J Clin Oncol Off J Am Soc Clin Oncol (2012) 30(21):2585-92. doi: 10.1200/jco.2011.35.6725

62. Baselga J, Bradbury I, Eidtmann H, Di Cosimo S, de Azambuja E, Aura C, et al. Lapatinib with trastuzumab for HER2-positive early breast cancer (NeoALTTO): a randomised, open-label, multicentre, phase 3 trial. Lancet (London England) (2012) 379(9816):633-40. doi: 10.1016/s0140-6736(11) 61847-3

63. Bonnefoi H, Jacot W, Saghatchian M, Moldovan C, Venat-Bouvet L, Zaman $\mathrm{K}$, et al. Neoadjuvant treatment with docetaxel plus lapatinib, trastuzumab, or both followed by an anthracycline-based chemotherapy in HER2-positive breast cancer: results of the randomised phase II EORTC 10054 study. Ann Oncol Off J Eur Soc Med Oncol (2015) 26(2):325-32. doi: 10.1093/annonc/ mdu551

64. Guarneri V, Frassoldati A, Bottini A, Cagossi K, Bisagni G, Sarti S, et al. Preoperative chemotherapy plus trastuzumab, lapatinib, or both in human epidermal growth factor receptor 2-positive operable breast cancer: results of the randomized phase II CHER-LOB study. J Clin Oncol Off J Am Soc Clin Oncol (2012) 30(16):1989-95. doi: 10.1200/jco.2011.39.0823

65. Robidoux A, Tang G, Rastogi P, Geyer CEJr., Azar CA, Atkins JN, et al. Lapatinib as a component of neoadjuvant therapy for HER2-positive operable breast cancer (NSABP protocol B-41): an open-label, randomised phase 3 trial. Lancet Oncol (2013) 14(12):1183-92. doi: 10.1016/s1470-2045(13) 70411-x

66. Holmes FA, Espina V, Liotta LA, Nagarwala YM, Danso M, McIntyre KJ, et al. Pathologic complete response after preoperative anti-HER2 therapy correlates with alterations in PTEN, FOXO, phosphorylated Stat5, and autophagy protein signaling. BMC Res Notes (2013) 6:507. doi: 10.1186/ 1756-0500-6-507

67. Takano T, Tsurutani J, Takahashi M, Yamanaka T, Sakai K, Ito Y, et al. A randomized phase II trial of trastuzumab plus capecitabine versus lapatinib plus capecitabine in patients with HER2-positive metastatic breast cancer previously treated with trastuzumab and taxanes: WJOG6110B/ELTOP. Breast (2018) 40:67-75. doi: 10.1016/j.breast.2018.04.010

68. Pivot X, Manikhas A, Żurawski B, Chmielowska E, Karaszewska B, Allerton R, et al. CEREBEL (EGF111438): A Phase III, Randomized, Open-Label Study of Lapatinib Plus Capecitabine Versus Trastuzumab Plus Capecitabine in Patients With Human Epidermal Growth Factor Receptor 2-Positive Metastatic Breast Cancer. J Clin Oncol (2015) 33(14):1564-73. doi: 10.1200/ JCO.2014.57.1794

69. Gril B, Palmieri D, Bronder JL, Herring JM, Vega-Valle E, Feigenbaum L, et al. Effect of lapatinib on the outgrowth of metastatic breast cancer cells to the brain. J Natl Cancer Inst (2008) 100(15):1092-103. doi: 10.1093/jnci/djn216

70. Taskar KS, Rudraraju V, Mittapalli RK, Samala R, Thorsheim HR, Lockman J, et al. Lapatinib distribution in HER2 overexpressing experimental brain metastases of breast cancer. Pharm Res (2012) 29(3):770-81. doi: 10.1007/ s11095-011-0601-8

71. Cochran DC, Chan MD, Aklilu M, Lovato JF, Alphonse NK, Bourland JD, et al. The effect of targeted agents on outcomes in patients with brain metastases from renal cell carcinoma treated with Gamma Knife surgery. J Neurosurg (2012) 116(5):978-83. doi: 10.3171/2012.2.Jns111353 
72. Seastone DJ, Elson P, Garcia JA, Chao ST, Suh JH, Angelov L, et al. Clinical outcome of stereotactic radiosurgery for central nervous system metastases from renal cell carcinoma. Clin Genitourinary Cancer (2014) 12(2):111-6. doi: 10.1016/j.clgc.2013.10.001

73. Ly D, Bagshaw HP, Anker CJ, Tward JD, Grossmann KF, Jensen RL, et al. Local control after stereotactic radiosurgery for brain metastases in patients with melanoma with and without BRAF mutation and treatment. J Neurosurg (2015) 123(2):395-401. doi: 10.3171/2014.9.Jns141425

74. Patel KR, Chowdhary M, Switchenko JM, Kudchadkar R, Lawson DH, Cassidy RJ, et al. BRAF inhibitor and stereotactic radiosurgery is associated with an increased risk of radiation necrosis. Melanoma Res (2016) 26(4):38794. doi: $10.1097 / \mathrm{cmr} .0000000000000268$

75. Cao Y, Tsien CI, Shen Z, Tatro DS, Ten Haken R, Kessler ML, et al. Use of magnetic resonance imaging to assess blood-brain/blood-glioma barrier opening during conformal radiotherapy. J Clin Oncol Off J Am Soc Clin Oncol (2005) 23(18):4127-36. doi: 10.1200/jco.2005.07.144

76. Truman JP, García-Barros M, Kaag M, Hambardzumyan D, Stancevic B, Chan $M$, et al. Endothelial membrane remodeling is obligate for antiangiogenic radiosensitization during tumor radiosurgery. PloS One (2010) 5 (8):e12310. doi: 10.1371/journal.pone.0012310

77. Verma J, Jonasch E, Allen PK, Weinberg JS, Tannir N, Chang EL, et al. The impact of tyrosine kinase inhibitors on the multimodality treatment of brain metastases from renal cell carcinoma. Am J Clin Oncol (2013) 36(6):620-4. doi: 10.1097/COC.0b013e31825d59db

78. Klausner G, Troussier I, Biau J, Jacob J, Schernberg A, Canova CH, et al. Stereotactic Radiation Therapy for Renal Cell Carcinoma Brain Metastases in the Tyrosine Kinase Inhibitors Era: Outcomes of 120 Patients. Clin Genitourinary Cancer (2019) 17(3):191-200. doi: 10.1016/j.clgc.2019.02.007

79. Xu Z, Lee CC, Ramesh A, Mueller AC, Schlesinger D, Cohen-Inbar O, et al. BRAF V600E mutation and BRAF kinase inhibitors in conjunction with stereotactic radiosurgery for intracranial melanoma metastases. J Neurosurg (2017) 126(3):726-34. doi: 10.3171/2016.2.Jns1633

80. Bachelot T, Romieu G, Campone M, Diéras V, Cropet C, Dalenc F, et al. Lapatinib plus capecitabine in patients with previously untreated brain metastases from HER2-positive metastatic breast cancer (LANDSCAPE): a single-group phase 2 study. Lancet Oncol (2013) 14(1):64-71. doi: 10.1016/ s1470-2045(12)70432-1

81. Shawky H, Tawfik H. All-oral combination of lapatinib and capecitabine in patients with brain metastases from HER2-positive breast cancer - A phase II study. J Egypt Natl Canc Instit (2014) 26(4):187-94. doi: 10.1016/j.jnci.2014.08.001

82. Kotecha R, Miller JA, Venur VA, Mohammadi AM, Chao ST, Suh JH, et al. Melanoma brain metastasis: the impact of stereotactic radiosurgery, BRAF mutational status, and targeted and/or immune-based therapies on treatment outcome. J Neurosurg (2018) 129(1):50-9. doi: 10.3171/2017.1.Jns162797

83. Juloori A, Miller J, Parsai S, Kotecha R, Ahluwalia M, Mohammadi A, et al. Overall survival and response to radiation and targeted therapies among patients with renal cell carcinoma brain metastases. J Neurosurg (2019) 132:19. doi: 10.3171/2018.8.JNS182100

84. Miller JA, Bennett EE, Xiao R, Kotecha R, Chao ST, Vogelbaum MA, et al. Association Between Radiation Necrosis and Tumor Biology After Stereotactic Radiosurgery for Brain Metastasis. Int J Radiat Oncol Biol Phys (2016) 96(5):1060-9. doi: 10.1016/j.ijrobp.2016.08.039

85. Sedgwick P S. Retrospective cohort studies: advantages and disadvantages. BMJ Br Med J (2014) 348:g1072. doi: 10.1136/bmj.g1072

86. Zhang J, Zhang L, Yan Y, Li S, Xie L, Zhong W, et al. Are capecitabine and the active metabolite 5-Fu CNS penetrable to treat breast cancer brain metastasis? Drug Metab Dispos (2015) 43(3):411-7. doi: 10.1124/dmd.114.061820
87. Breedveld P, Beijnen JH, Schellens JH. Use of P-glycoprotein and BCRP inhibitors to improve oral bioavailability and CNS penetration of anticancer drugs. Trends Pharmacol Sci (2006) 27(1):17-24. doi: 10.1016/j.tips.2005. 11.009

88. Lagas JS, van Waterschoot RA, van Tilburg VA, Hillebrand MJ, Lankheet N, Rosing $\mathrm{H}$, et al. Brain accumulation of dasatinib is restricted by $\mathrm{P}$-glycoprotein (ABCB1) and breast cancer resistance protein (ABCG2) and can be enhanced by elacridar treatment. Clin Cancer Res Off J Am Assoc Cancer Res (2009) 15 (7):2344-51. doi: 10.1158/1078-0432.Ccr-08-2253

89. Durmus S, Sparidans RW, Wagenaar E, Beijnen JH, Schinkel AH. Oral availability and brain penetration of the B-RAFV600E inhibitor vemurafenib can be enhanced by the P-GLYCOprotein (ABCB1) and breast cancer resistance protein (ABCG2) inhibitor. Mol Pharm (2012) 9(11):323645. doi: $10.1021 / \mathrm{mp} 3003144$

90. Tang SC, Lagas JS, Lankheet NA, Poller B, Hillebrand MJ, Rosing H, et al. Brain accumulation of sunitinib is restricted by P-glycoprotein (ABCB1) and breast cancer resistance protein (ABCG2) and can be enhanced by oral elacridar and sunitinib coadministration. Int J Cancer (2012) 130(1):223-33. doi: $10.1002 /$ ijc. 26000

91. Tang SC, Nguyen LN, Sparidans RW, Wagenaar E, Beijnen JH, Schinkel AH. Increased oral availability and brain accumulation of the ALK inhibitor crizotinib by coadministration of the P-glycoprotein (ABCB1) and breast cancer resistance protein (ABCG2) inhibitor elacridar. Int J Cancer (2014) 134 (6):1484-94. doi: 10.1002/ijc.28475

92. Karbownik A, Sobańska K, Płotek W, Grabowski T, Klupczynska A, Plewa S, et al. The influence of the coadministration of the p-glycoprotein modulator elacridar on the pharmacokinetics of lapatinib and its distribution in the brain and cerebrospinal fluid. Invest New Drugs (2020) 38(3):574-83. doi: 10.1007/ s10637-019-00806-3

93. Diéras V, Miles D, Verma S, Pegram M, Welslau M, Baselga J, et al. Trastuzumab emtansine versus capecitabine plus lapatinib in patients with previously treated HER2-positive advanced breast cancer (EMILIA): a descriptive analysis of final overall survival results from a randomised, open-label, phase 3 trial. Lancet Oncol (2017) 18(6):732-42. doi: 10.1016/ s1470-2045(17)30312-1

94. Carlson JA, Nooruddin Z, Rusthoven C, Elias A, Borges VF, Diamond JR, et al. Trastuzumab emtansine and stereotactic radiosurgery: an unexpected increase in clinically significant brain edema. Neuro Oncol (2014) 16(7):10069. doi: 10.1093/neuonc/not329

95. Mitsuya K, Watanabe J, Nakasu Y, Hayashi N, Harada H, Ito I. Expansive hematoma in delayed cerebral radiation necrosis in patients treated with TDM1: a report of two cases. BMC Cancer (2016) 16:391. doi: 10.1186/s12885016-2464-1

96. Fares J, Kanojia D, Cordero A, Rashidi A, Miska J, Schwartz CW, et al. Current state of clinical trials in breast cancer brain metastases. Neuro Oncol Pract (2019) 6(5):392-401. doi: 10.1093/nop/npz003

Conflict of Interest: The authors declare that the research was conducted in the absence of any commercial or financial relationships that could be construed as a potential conflict of interest.

Copyright (C) 2020 Khan, Zhao, Arooj, Zheng and Liao. This is an open-access article distributed under the terms of the Creative Commons Attribution License (CC BY). The use, distribution or reproduction in other forums is permitted, provided the original author(s) and the copyright owner(s) are credited and that the original publication in this journal is cited, in accordance with accepted academic practice. No use, distribution or reproduction is permitted which does not comply with these terms. 